\title{
ЕФЕКТИВНІСТЬ ЗАСТОСУВАННЯ РЕАБІЛІТАЦІЙНИХ ВТРУЧАНЬ ПРИ ДІАБЕТИЧНІЙ ПОЛІНЕЙРОПАТІЇ В УМОВАХ СТАЦІОНАРНОГО ЛІКУВАННЯ
}

\author{
๑Т. Г. Бакалюк, Н. Р. Макарчук, Г. О. Стельмах
}

Тернопільський національний медичний університет імені І. Я. Горбачевського, МОз України

РЕзЮМЕ. У пацієнтів із цукровим діабетом 2-го типу та діабетичною полінейропатією додавання до основних схем лікування в стаціонарі дозованої лікувальної ходьби та поляризуючого світла відновлює всі види чутливості та покращує якість життя.

Мета - дослідити вплив комплексного лікування на відновлення чутливості у хворих з діабетичною полінейропатією шляхом включення до стандартних медикаментозних схем лікування дозованої лікувальної ходьби та поляризуючого світла.

Матеріал і методи. Обстежено 95 пацієнтів з цукровим діабетом 2-го типу та діабетичною полінейропатією. Пацієнтів було поділено на три групи: I група отримувала протокольне лікування, II група додатково до протокольного лікування отримувала процедури з використанням поляризуючого світла, в III групі до стандартного лікування додатково включали дозовану лікувальну ходьбу та поляризуюче світло. Оцінку неврологічного статусу проводили шляхом визначення поверхневих (тактильної, больової, температурної) та глибокої (вібраційної) видів чутливості.

Результати. У всіх групах виявлена позитивна динаміка змін (відновлення) чутливості. В 1-й групі найбільше відновилася больова чутливість, у 2-й - температурна, больова та тактильна. Найкращий ефект від лікування виявлено у 3-й групі, де достовірно відновилися всі види чутливості. Порівняння результатів лікування між групами виявило вірогідно кращі результати щодо відновлення вібраційної чутливості у пацієнтів, які отримували процедури поляризуючим світлом та дозовану лікувальну ходьбу (на тредмілі) у комплексному лікуванні діабетичної полінейропатії.

Висновки. Додаткове призначення хворим із діабетичною полінейропатією до стандартної терапії дозованої лікувальної ходи та поляризуючого світла вірогідно ефективніше впливає на відновлення тактильної, больової, температурної та вібраційної чутливості, порівняно з іншими лікувальними комплексами. Такий підхід до призначення реабілітаційних втручань у пацієнтів з діабетичною полінейропатією в стаціонарних умовах може бути запропонований для використання на різних етапах реабілітації.

КлючовІ СлОВА: цукровий діабет; діабетична полінейропатія; дозована лікувальна ходьба; поляризуюче світло.

Вступ. Одним із найпоширеніших ускладнень цукрового діабету (ЦД), що найважче піддається лікуванню, $\epsilon$ діабетична полінейропатія (ДПН) [1]. Вона характеризується прогресуючою загибеллю нервових волокон та призводить до порушень вібраційної, тактильної, больової та температурної чутливості, зокрема ії дистальна форма [2]. Саме тому велике значення у хворих на ЦД мають своєчасна діагностика ДПН та коректне (адекватне) лікування.

Сучасна патогенетична терапія ДПН включає призначення препаратів альфа-ліпоєвої кислоти, актовегіну, вітамінів групи В [3]. Окрім медикаментозних методів, все більше уваги приділяється засобам немедикаментозної терапії, зокрема, світлотерапевтичним процедурам із застосуванням поляризуючого світла [4, 5], які показали позитивні результати у лікуванні нейропатії різної етіології.

У людей із цД і патологією нижніх кінцівок, таких як ДПН, ризик, обумовлений обмеженою рухливістю, збільшується майже в 3 рази, порівняно з тими, у кого немає ні того, ні іншого. Також збільшується ризик обмеження рухливості серед літніх людей, які страждають від ЦД $[6,7]$.
Незважаючи на значні дослідження, що свідчать про переваги помірної інтенсивності фізичної активності (наприклад, швидка ходьба) для тих, хто має ЦД [8, 9], було проведено дослідження наслідків вправ серед людей з ЦД і ДПН, можливо, внаслідок заклопотаності з приводу можливого травмування нечутливої ноги учасників і скептичним ставленням до того, що вправи можуть бути корисними. Історично людям з ЦД та ДПН рекомендували уникати фізичної активності, але бездіяльність може сприяти погіршенню стану шкіри і зниженню толерантності до навантажень [10]. Кілька досліджень дають докази на підтримку гіпотези про те, що менш активні люди з ЦД і ДПН схильні до більшого ризику руйнування шкіри, ніж активніші $[10,11]$.

Аналізуючи літературні дані ми прийшли до висновку, що поєднання медикаментозного лікування з фізіотерапевтичними процедурами та фізичними навантаженнями при лікуванні дПН може бути доцільним.

Мета - вивчити вплив комплексного лікування на відновлення чутливості у хворих із діабетичною полінейропатією шляхом включення 
Огляди літератури, оригінальні дослідження, погляд на проблему, випадок з практики, короткі повідомлення до стандартних медикаментозних схем лікування дозованої лікувальної ходьби та поляризуючого світла.

Матеріал і методи дослідження. Обстежено 95 хворих на ЦД 2-го типу та ДПН. Вік обстежених становив від 45 до 65 років (середній вік $(58,5 \pm 2,8)$ роки). Тривалість ЦД склала від 7 до 21 року (середня тривалість $(9,9 \pm 4,5)$ роки), а ДПН 1-13 років (середня тривалість $(5,5 \pm 2,6)$ роки). Серед обстежених було 50 (52,5 \%) чоловіків і 45 $(47,5 \%)$ жінок.

Критеріями включення в дослідження були підписання пацієнтами інформованої згоди; наявність ЦД 2-го типу понад 1 рік; діагностована ДПН, дистальний симетричний тип, сенсорна форма; вік від 45 до 65 років.

Критеріями виключення із дослідження були: ЦД 1-го типу; наявність гострих ускладнень ЦД; ознаки інших типів полінейропатії; наявність вертеброгенного больового синдрому; деформація стопи, яка потребує виготовлення індивідуального взуття; виразкові дефекти стоп II-IV ступенів тяжкості, ампутація стопи, нижньої кінцівки; прояви вираженої дихальної недостатності з тяжкою CH (III - IV ФК за NYHA); нестабільна стенокардія, інфаркт міокарда, транзиторна ішемічна атака, інсульт за 3 місяці до включення у дослідження

Усі пацієнти отримували стандартну терапію ДПн відповідно до уніфікованого протоколу [12].

Усі обстежені були поділенні на 3 групи: до контрольної групи (I група) увійшли 32 пацієнти, які отримували стандартне лікування згідно з уніфікованим клінічним протоколом первинної та вторинної (спеціалізованої) медичної допомоги (№ 1118 від 21.12.2012) [12]. 32 пацієнтам II дослідної групи додатково було призначено 12 лікувальних процедур поляризуючим світлом. 31 пацієнту III групи, окрім стандартного лікування та процедур поляризуючим світлом № 12, було призначено дозовану лікувальну ходьбу (на тредмілі) № 12.

Оцінку неврологічного статусу проводили шляхом визначення поверхневих (тактильної, больової, температурної) та глибокої (вібраційної) видів чутливості. Тактильну чутливість визначали за допомогою монофіламенту калібру 5,07 (що згинається під впливом сили в 10 г), на симетричних ділянках стопи (тильна поверхня, плантарна поверхня плесно-фалангових суглобів, апікальні поверхні пальців і п'ята). Порушення тактильної чутливості реєстрували тоді, коли пацієнт не відчував доторків монофіламенту хоча 6 в одній точці стопи (вільної від гіперкератозу та мозолів) [13].

Визначення больової чутливості проводили за допомогою притупленої (атравматичної) голки, якою наносили легкі уколи.

Порушення температурної чутливості вимірювали шляхом почергового доторкання до симетричних ділянок стопи за допомогою циліндра Tip-Term, кінці якого мають різну температуру. Температурну чутливість вважали втраченою при нездатності хворого розрізняти вказані подразники.

Для оцінки вібраційної чутливості застосовували камертон 128 Гц. Для цього ніжку камертона встановлювали на симетричні ділянки шкіри в проекції кісткових виступів та вимірювали час відчуття вібрації. За об'єктивну ознаку порушення вібраційної чутливості приймали зменшення тривалості сприйняття тремтіння камертона (норма 15-20 секунд) та різницю сприйняття у симетричних точках [13].

Щоденно проводили візуальний огляд ніг учасника. Ураження шкіри на гомілці контролювали, щоб підтвердити безпечність втручання.

Тривалість та інтенсивність занять на тредмілі підбирали індивідуально. Цільова частота серцевих скорочень повинна була складати від 60 \% до 70 \% від прогнозованого максимуму, а активність була скоригована так, щоб залишатися в цих межах, з використанням пульсометра і оцінки сприйманого навантаження від 11 до 13 за шкалою від 6 до 20 [14].

Аналіз й обробку статистичних даних клінічних обстежень проводили на персональному комп'ютері з використанням пакета прикладних програм STATISTICA 10 та MS Excel XP. Зіставлення між групами проводили за допомогою порівняння середніх рангових і вважали їх достовірними при p<0,05. Достовірність розбіжностей між групами розраховували на базі функцій ANOVA-статистики. Порівняння абсолютних величин здійснювалося за допомогою критерію Пірсона $\chi^{2}$ (хіквадрат). Різницю показників вважали вірогідною при показнику $р<0,05$.

Результати й обговорення. Значимих відмінностей між групами до лікування не було ( $>0,05)$. До лікування зниження температурної чутливості виявлено у 19 (59,38 \%) хворих I групи, у $21(65,6 \%)$ хворого II групи, у 20 (64,5 \%) хворих III групи; больової чутливості у 20 (62,5 \%), 16 (50\%) та 17 (54,8 \%) відповідно. Тактильна та вібраційна чутливість були знижені у 25 (78,1\%) і 27 (84,4 \%) хворих I групи, в 22 (68,5 \%) і 25 (78,1\%) хворих II групи та у 23 (74,2 \%) і 27 (87\%) обстежених III групи.

На рисунку 1 показано порівняння показників чутливості в трьох групах обстежених до і після проведеного лікування.

До лікування у всіх групах обстежених найбільше була знижена вібраційна і тактильна чутливість, менше - больова та температурна. 
Огляди літератури, оригінальні дослідження, погляд на проблему, випадок з практики, короткі повідомлення
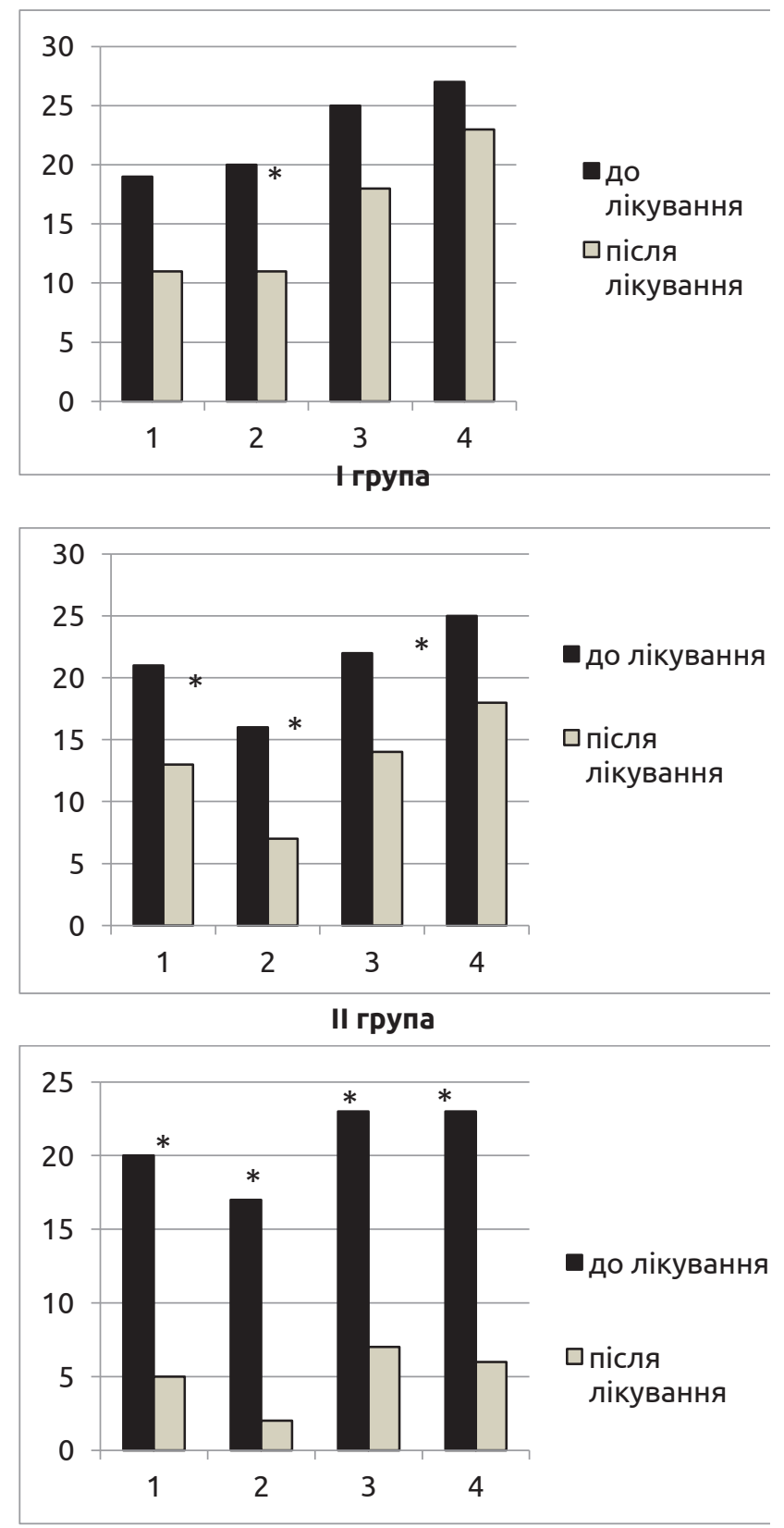

III група

Рис. 1. Динаміка відновлення чутливості в групах обстежених хворих під впливом використаних програм лікування.

Примітки: 1 - температурна чутливість; 2 - больова чутливість; 3 - тактильна чутливість; 4 - вібраційна чутливість; * достовірність різниці показників у групі до і після лікування, $\mathrm{p}<0,05$.
До лікування у всіх групах обстежених найбільше була знижена вібраційна і тактильна чутливість, менше - больова та температурна.

Після застосування лікувальних комплексів у хворих усіх груп спостерігалася позитивна динаміка змін (відновлення) чутливості. В I групі найбільше відновилася больова чутливість, у II - температурна, больова та тактильна.

Найкращий ефект від лікування виявлено у пацієнтів III групи, в яких достовірно відновилися всі види поверхневої чутливості.

Також порівняння результатів лікування між групами виявило вірогідно кращі результати щодо відновлення вібраційної чутливості у групі пацієнтів, які отримували процедури поляризуючим світлом та дозовану лікувальну ходьбу (на тредмілі) у комплексному лікуванні ДПН.

Після застосування лікувальних комплексів не відновилась температурна чутливість у 11 (34,4 \%) $\left(\chi^{2}=3,065 ;\right.$ р>0,05) хворих І групи, у $13(40,6 \%)$ $\left(\chi^{2}=4,016 ;\right.$ р<0,05) хворих II групи, у 20 (64,5\%) $\left(\chi^{2}=15,001 ; p<0,05\right)$ хворих III групи.

Больова чутливість не відновилась у 11 (34,4\%) $\left(\chi^{2}=5,067 ;\right.$ р<0,05) пацієнтів I, у $7(21,9 \%)\left(\chi^{2}=5,497\right.$; p<0,05) обстежених II групи та у $2(6,5 \%)\left(\chi^{2}=17,07\right.$; $\mathrm{p}<0,05)$ пацієнтів III групи.

Тактильна та вібраційна чутливість не відновилась у $18(56,25 \%)\left(\chi^{2}=3,473 ;\right.$ p>0,05) і в $23(71,8 \%)$ $\left(\chi^{2}=1,463 ;\right.$ p<0,05) пацієнтів І групи, в $14(43,75 \%)$ $\left(\chi^{2}=4,063 ; p<0,05\right)$ i $18(56,25 \%)\left(\chi^{2}=3,473 ; p>0,05\right)$ хворих II групи та у $2(6,5 \%)\left(\chi^{2}=29,56\right.$; р<0,05) і 4 $(12,9 \%)\left(\chi^{2}=23,68 ; p<0,05\right)$ обстежених III групи відповідно (див. рис. 1).

Висновки. Додаткове призначення хворим із діабетичною полінейропатією до стандартної терапії дозованої лікувальної ходи та поляризуючого світла вірогідно ефективніше впливає на відновлення тактильної, больової, температурної та вібраційної чутливості, порівняно з іншими лікувальними комплексами. Такий підхід до призначення реабілітаційних втручань у пацієнтів з діабетичною полінейропатією в стаціонарних умовах може бути запропонований для використання на різних етапах реабілітації.

Перспективи подальших досліджень. Плануємо вивчити вплив лікувального комплексу із включеннямпроцедур поляризуючого світлаталікувальної дозованої ходьби на показники якості життя. 


\section{ЛІТЕРАТУРА}

1. Храмилин В.Н. Диагностика и лечение ранних стадий диабетической полинейропатии / В. Н. Храмилин, А. Н. Завьялов, И. Ю. Демидова // Медицинский совет. - 2020. - № 7. - С. 56-65.

2. Алгоритмы специализированной медицинской помощи больным сахарным диабетом (5-й выпуск) / И. И. Дедов, М. В. Шестакова, А. А. Александров [и др.] // Сахарный диабет. - 2011. - № 3. - Р. 40-42.

3. Emerging biomarkers, tools, and treatments for diabetic polyneuropathy / G. J. Bönhof, C. Herder, A. Strom [et al.] // Endocr. Rev. - 2019. - Vol. 40. - P. 153-192.

4. Застосування біоптрон-пайлер-світла в медицині (терапія низькоінтенсивними поляризованими електромагнітними хвилями оптично-інфрачервоного діапазону) : навч.-метод. посіб. / С. О. Гуляр, А. Л. Косаковський. - К., 2006. -152 с.

5. Шляхи покращення якості життя хворих з діабетичною полінейропатією / Л. П. Мартинюк, М. І. Швед, H. Р. Макарчук, В. І. Чернецький. // East Eur. Sci. J. - 2018. № 1 (29), ч. 1. - C. 39-43.

6. Weight-bearing versus nonweight-bearing exercise for persons with diabetes and peripheral neuropathy: a randomized controlled trial / M. J. Mueller, L. J. Tuttle, J. W. Lemaster [et al.] // Arch. Phys. Med. Rehabil. - 2013. Vol. 94 (5). - P. 829-838.

7. Centers for Disease Control and Prevention (CDC). Mobility limitation among persons aged $>$ or $=40$ years with and without diagnosed diabetes and lower extremity disease-United States, 1999-2002 // Morb. Mortal. Wkly. Rep. - 2005. - Vol. 54 (46). - P. 1183-1186.

\section{REFERENCES}

1. Khramylyn, V.N., Zavyalov, A.N., \& Demydova, Y. Yu. (2020). Diagnostika i lecheniye rannikh stadiy diabeticheskoy polineyropatii [Diagnostics and treatment of early stages of diabetic polyneuropathy]. Medytsynskyj sovet Medical Council, 7, 56-65. DOI: 10.21518/2079-701X-20207-56-65 [in Russian].

2. Dedov, I.I., Shestakova, M.V., Aleksandrov, A.A., Galstyan, G.R., Grigoryan, O.R., Yesayan, R.M., ..., \& YarekMartynova, I.R. (2011). Algoritmy spetsializirovannoy meditsinskoy pomoshchi bolnym sakharnym diabetom (5-y vypusk) [Algorithms of specialized medical care for patients with diabetes mellitus (5th edition)]. Sakharnyy diabet - Diabetes Mellitus, 3, 40-42 [in Russian].

3. Bonhof, G.J., Herder, C., Strom, A., Papanas, N., Roden, M., \& Ziegler, D. (2019). Emerging biomarkers, tools, and treatments for diabetic polyneuropathy. Endocr. Rev., 40, 153-192. DOI:10.1210/er.2018-00107.

4. Huliar, S.O., \& Kosakovskyi, A.L. (2006). Zastosuvannia bioptron-pailer-svitla $v$ medytsyni (terapiia nyzkointensyvnymy poliaryzovanymy elektromahnitnymy khvyliamy optychno-infrachervonoho diapazonu) [Application of bioptron-pailer-light in medicine (therapy with low-intensity polarized electromagnetic waves of optical-infrared range)]. Educ. Manual. Kyiv [in Ukrainian].

5. Martynyuk, L.P., Shved, M.I., Makarchuk, N.R., \& Chernetskyi, V.I. (2018). Shliakhy pokrashchennia yakosti
8. Relationship of walking to mortality among US adults with diabetes / E. W. Gregg, R. B. Gerzoff, C. J. Caspersen [et al.] // Arch. Intern. Med. - 2003. - Vol. 163 (12). P. $1440-1447$.

9. American College of Sports Medicine; American Diabetes Association. Exercise and type 2 diabetes: the American College of Sports Medicine and the American Diabetes Association: joint position statement / S. R. Colberg, R. J. Sigal, B. Fernhall [et al.] // Diabetes Care. - 2010. Vol. 33 (12). - P. 147-167.

10. Effect of weight-bearing activity on foot ulcer incidence in people with diabetic peripheral neuropathy: feet first randomized controlled trial / J. W. Lemaster, M. J. Mueller, G. E. Reiber [et al.] // Phys. Ther. - 2008. Vol. 88 (11). - P. 1385-1398.

11. Variability in activity may precede diabetic foot ulceration / D. G. Armstrong, L. A. Lavery, K. Holtz-Neiderer [et al.] // Diabetes Care. - 2004. - Vol. 27 (8). - P. 1980-1984.

12. Міністерство охорони здоров'я України. Уніфікований клінічний протокол первинної та вторинної (спеціалізованої) медичної допомоги - цукровий діабет 2 типу : наказ МОЗ України № 1118 від 21.12.2012. - URL: www/moz.qov.ua/ua/portal/dn_20121221_1118.html.

13. Афанасьев Д. Е. Доступные методы диагностики диабетической дистальной симметричной полинейропатии / Д. Е. Афанасьев // Новая медицина тысячелетия. - 2006. - № 6. - С. 33-36.

14. Physical activity/exercise and type 2 diabetes: a consensus statement from the American Diabetes Association / R. J. Sigal, G. P. Kenny, D. H. Wasserman [et al.] // Diabetes Care. - 2006. - Vol. 29 (6). - P. 1433-1438.

zhyttia khvorykh z diabetychnoiu polineiropatiieiu [Ways to improve the quality of life of patients with diabetic polyneuropathy]. East Eur. Sci. J., 1 (29), 39-41 [in Ukrainian].

6. Mueller, M.J., Tuttle L.J., Lemaster, J.W., Strube, M.J., McGill, J.B., Hastings, M.K., \& Sinacore, D.R. (2013). Weight-bearing versus nonweight-bearing exercise for persons with diabetes and peripheral neuropathy: a randomized controlled trial. Arch. Phys. Med. Rehabil., 94 (5), 829838. DOI:10.1016/j.apmr.2012.12.015.

7. Centers for Disease Control and Prevention (CDC) (2005). Mobility limitation among persons aged > or $=40$ years with and without diagnosed diabetes and lower extremity disease--United States, 1999-2002. Morb. Mortal. Wkly. Rep., 54 (46), 1183-1186.

8. Gregg, E.W., Gerzoff, R.B., Caspersen, C.J., Williamson, D.F., \& Narayan, K.M. (2003). Relationship of walking to mortality among US adults with diabetes. Arch. Intern. Med., 163 (12), 1440-1447. DOI:10.1001/ archinte.163.12.1440.

9. Colberg, S.R., Sigal, R.J., Fernhall, B., Regensteiner, J.G., Blissmer, B.J., Rubin, R.R., ..., \& Braun, B. (2010). American College of Sports Medicine; American Diabetes Association. Exercise and type 2 diabetes: the American College of Sports Medicine and the American Diabetes Association: joint position statement. Diabetes Care, 33 (12), e147-67. DOI:10.2337/dc10-9990. 
Огляди літератури, оригінальні дослідження, погляд на проблему, випадок з практики, короткі повідомлення

10. Lemaster, J.W., Mueller, M.J., Reiber, G.E., Mehr, D.R., Madsen, R.W., \& Conn, V.S. (2008). Effect of weight-bearing activity on foot ulcer incidence in people with diabetic peripheral neuropathy: feet first randomized controlled trial. Phys. Ther., 88 (11), 1385-1398. DOI:10.2522/ptj.20080019.

11. Armstrong, D.G., Lavery, L.A., Holtz-Neiderer, K., Mohler, M.J., Wendel, C.S., Nixon, B.P., \& Boulton, A.J. (2004). Variability in activity may precede diabetic foot ulceration. Diabetes Care, 27 (8), 1980-1984. DOI:10.2337/ diacare.27.8.1980.

12. (2012). Ministerstvo okhorony zdorovia Ukrainy. Unifikovanyi klinichnyi protokol pervynnoi ta vtorynnoi (spetsializovanoi) medychnoi dopomohy - tsukrovyi diabet 2 typu. Nakaz Ministerstva okhorony zdorovia Ukrainy [Ministry of
Health of Ukraine. Unified clinical protocol for primary and secondary (specialized) - type 2 diabetes. Order of the Ministry of Health of Ukraine]. No. 1118, 21.12.2012. Retrieved from: www/moz.qov.ua/ua/portal/dn_20121221_1118.html [in Ukrainian].

13. Afanasyev, D.Ye. (2006). Dostupnyye metody diagnostiki diabeticheskoy distalnoy simmetrichnoy polineyropatii [Available methods for diagnosing diabetic distal symmetric polyneuropathy]. Novaya meditsina tysyacheletiya-New Medicine of the Millennium, 6, 33-36 [in Russian].

14. Sigal, R.J., Kenny, G.P., Wasserman, D.H., Castaneda-Sceppa, C., \& White, R.D. (2006). Physical activity/ exercise and type 2 diabetes: a consensus statement from the American Diabetes Association. Diabetes Care, 29 (6), 1433-1438. DOI:10.2337/dc06-9910.

\title{
ЭФФЕКТИВНОСТЬ ПРИМЕНЕНИЯ РЕАБИЛИТАЦИОННЫХ ВМЕШАТЕЛЬСТВ ПРИ ДИАБЕТИЧЕСКОЙ ПОЛИНЕЙРОПАТИИ В УСЛОВИЯХ СТАЦИОНАРНОГО ЛЕЧЕНИЯ
}

\author{
○Т. Г. Бакалюк, Н. Р. Макарчук, Г. О. Стельмах
}

Тернопольский национальный медицинский университет имени И. Я. Горбачевского МОз Украины

РЕЗЮМЕ. У пациентов с сахарным диабетом 2-го типа и диабетической полинейропатией добавление к основным схемам лечения в стационаре методов дозированной лечебной ходьбы и поляризующего света восстанавливает все виды чувствительности и улучшает качество жизни.

Цель - исследовать влияние комплексного лечения на восстановление чувствительности у больных диабетической полинейропатией путем включения в стандартные медикаментозные схемы лечения дозированной лечебной ходьбы и поляризующего света.

Материал и методы. Обследовано 95 пациентов с сахарным диабетом 2-го типа и диабетической полинейропатией. Пациенты были поделены на три группы: I группа получала протокольное лечение, II группа дополнительно к протокольному лечению получала процедуры поляризующим светом, в III группе в стандартное лечение дополнительно включало дозированную лечебную ходьбу и процедуры поляризующим светом. Оценку неврологического статуса проводили путем определения поверхностных (тактильной, болевой, температурной) и глубокой (вибрационной) видов чувствительности.

Результаты. Во всех группах наблюдалась положительная динамика изменений (восстановление) чувствительности. В I группе больше восстановилась болевая чувствительность, во II - температурная, болевая и тактильная. Наилучший эффект от лечения выявлен в III группе, в которой достоверно возобновились все виды чувствительности. Сравнение результатов лечения между группами выявило достоверно лучшие результаты восстановления вибрационной чувствительности у пациентов, получавших процедуры поляризующим светом и дозированную лечебную ходьбу (на тредмиле) в комплексном лечении диабетической полинейропатии.

Выводы. Дополнительное назначение больным диабетической полинейропатией к стандартной терапии дозированной лечебной ходьбы и поляризующего света достоверно эффективнее влияет на восстановление тактильной, болевой, температурной и вибрационной чувствительности, по сравнению с другими лечебными комплексами. Такой подход к назначению реабилитационных вмешательств у пациентов с диабетической полинейропатией в стационарных условиях может быть предложен для использования на различных этапах реабилитации.

КЛЮчЕВЫЕ СЛОВА: сахарный диабет; диабетическая полинейропатия; дозированная лечебная ходьба; поляризирующий свет.

\section{EFFECTIVENESS OF REHABILITATION INTERVENTIONS IN DIABETIC POLYNEUROPATHY IN CONDITIONS OF INPATIENT TREATMENT}

\author{
@T. H. Bakaliuk, N. R. Makarchuk, H. O. Stelmakh \\ I. Horbachevsky Ternopil National Medical University
}

SUMMARY. In patients with type 2 diabetes mellitus and diabetic polyneuropathy, the addition of dosed therapeutic gait and polarizing light to the main treatment regimens in the hospital restores all types of sensitivity and improves the quality of life. 
Огляди літератури, оригінальні дослідження, погляд на проблему, випадок з практики, короткі повідомлення

The aim - to study the effect of complex treatment on the restoration of sensitivity in patients with diabetic polyneuropathy by including dosed therapeutic gait and polarizing light in standard treatment regimens.

Material and Methods. 95 patients with type 2 diabetes mellitus and diabetic polyneuropathy were examined. Patients were divided into 3 groups: group 1 received protocol treatment, group 2 in addition to protocol treatment received procedures with polarizing light, group 3 - the standard treatment additionally included dosed therapeutic gait and polarizing light. Assessment of neurological status was performed by determining superficial (tactile, pain, temperature) and deep (vibrational) types of sensitivity.

Results. In all groups there was a positive dynamics of changes (recovery) of sensitivity. In group 1 - the most restored pain sensitivity in group 2 - temperature, pain and tactile. The best effect of treatment was found in group 3 , where all types of sensitivity were reliably restored. Comparison of treatment outcomes between the groups showed significantly better results in terms of restoring vibration sensitivity in patients who received procedures with polarizing light and dosed therapeutic gait (on a treadmill) in the complex treatment of diabetic polyneuropathy.

Conclusions. The additional appointment of patients with diabetic polyneuropathy to the standard therapy of dosed therapeutic course and polarizing light is likely to have a more effective effect on the restoration of tactile, pain, temperature and vibrational sensitivity compared to other therapeutic complexes. This approach to the appointment of rehabilitation interventions in patients with diabetic polyneuropathy in an inpatient setting can be proposed for use at different stages of rehabilitation.

KEY WORDS: diabetes mellitus; diabetic polyneuropathy; dosed therapeutic gait; polarizing light.

Отримано 08.10.2020 